\title{
Inert gas narcosis: Avoidance behavior in rats breathing elevated pressures of nitrogen and helium
}

\author{
JOHN R. THOMAS and LINDA S. BURCH \\ Behavioral Sciences Department, Naval Medical Research Institute, Bethesda, Maryland 20014
}

\begin{abstract}
Avoidance response rates generated by a free-operant avoidance schedule with a response-shock interval of $20 \mathrm{sec}$ and a shock-shock interval of $2 \mathrm{sec}$ increased when rats breathed raised pressures of nitrogen up to 19 times normal atmospheric pressure. Further, nitrogen pressure increases to over 30 times normal pressure produced decreases in avoidance rates and disruption of temporal discrimination reflected by changes in conditional probabilities of interresponse times. Changes in avoidance response rates and shock frequencies were related to increases in nitrogen partial pressures rather than total absolute pressure as oxygen and carbon dioxide partial pressures were kept at normal atmospheric levels, and similar avoidance performance changes did not occur at identical pressures breathing helium. Increased helium pressures produced increases in avoidance responding at 25 to 30 times normal atmospheric pressure that were similar to effects of nitrogen at lower pressures, indicating that nitrogen is about four times as potent as helium in terms of narcotic effects on avoidance behavior.
\end{abstract}

Air is capable of producing narcosis and intoxication if it is breathed under sufficient increased pressure (Bennett, 1965, 1966, 1969; Miles, 1969). The signs and symptoms of the narcosis are reported as similar to those due to alcohol, hypoxia, and the early stages of anesthesia (Bennett, 1969). Such symptoms occur when organisms breathe compressed air at pressures higher than four to five times that of normal atmospheric pressure (e.g., breathing compressed air while exposed to pressures from surrounding water when diving deeper than 30 to $40 \mathrm{~m}$, or when breathing elevated pressures of air in hyperbaric environments such as pressure chambers and pressurized caissons and tunnels).

The effects of these pressures have been termed nitrogen narcosis, based on the early suggestions of Behnke and associates that the increased nitrogen partial pressure component of air is responsible for the behavioral and physiological effects (Behnke, Thompson, \& Motley, 1935; Behnke \& Yarbrough, 1939). More recently, the term inert gas narcosis has been used (Bennett. 1969) as evidence has accumulated that other gases at raised pressures produce similar behavioral and physiological effects, varying only in their potency.

Operant baselines recently have been used to assess the effects of raised nitrogen pressures on behavior. Low rates of responding maintained by food reinforcement schedules, such as differentialreinforcement-of-low-rate (DRL) schedules, have been found to increase selectively under raised nitrogen pressures (Jennings, 1973; Thomas, 1973a, 1974; Walsh \& Bachrach, 1974; Thomas, Walsh,

From Bureau of Medicine and Surgery, Navy Department, Research Subtask MF51.524.004.7007DX9K. The opinions and statements contained herein are the private ones of the writers and are not to be construed as official or reflecting the views of the Navy Department or the naval service at large.
Bachrach, \& Thorne, Note 1). Thomas and Burch (1975) extended these findings to a low-rate behavioral baseline maintained by avoidance of electrical shock. Increases in response rates on the free-operant avoidance schedule were related to raised partial pressures of nitrogen, and rate increases were not associated with disruption of temporal discrimination as reflected by the distribution of responses in time.

The present study sought to extend the analysis of nitrogen pressures on avoidance behavior to much higher partial pressures than explored previously, equivalent to pressures obtained at $305 \mathrm{~m}(1,000 \mathrm{ft})$ of sea water, and to establish a pressure-response function over such a range of pressures. It was of interest to examine the integrity of the temporal discrimination on the avoidance schedule at much greater nitrogen pressures than investigated previously, as other low-rate baselines (such as DRL) have shown further rate increases at higher pressures to be associated with disruption of temporal discriminations (Thomas, 1974). An additional interest of the present study was the examination of raised pressure effects on avoidance behavior while carefully maintaining oxygen partial pressures within normal ranges, since it has been shown that nitrogen effects on behavior are modified by raised oxygen pressures (Frankenhaeuser, Graff-Lonnevig, \& Hesser, 1960. 1963; Thomas, 1974). Another aspect of the study was to explore the effects of elevated pressures of helium on avoidance behavior and to compare' its behavioral effects with nitrogen.

\section{METHODS}

\footnotetext{
Subjects

The subjects were eight male albino rats (NMRI:0 [SD], Sprague-Dawley derived), weighing between 250 and $300 \mathrm{~g}$. They were housed in individual home cages with continual access to food and water. ${ }^{1}$
} 


\section{Apparatus}

The experimental chamber was a rat cage, $21.6 \mathrm{~cm}$ wide $\mathrm{x}$ $24.1 \mathrm{~cm}$ long $\times 20.3 \mathrm{~cm}$ high, made with aluminum front and back walls and perforated Plexiglas sides and top. Eighteen $0.16-\mathrm{cm}$ stainless steel grids, mounted $1.3 \mathrm{~cm}$ apart, comprised the cage floor. A rat lever that required a minimum force of $0.10 \mathrm{~N}$ to operate was mounted on the front wall $2.5 \mathrm{~cm}$ above the grid floor. A small red light was located $5.1 \mathrm{~cm}$ above the lever and a houselight was mounted in the center of the front wall $2.5 \mathrm{~cm}$ from the top. During most baseline sessions, the rat cage was mounted inside a sound-reducing enclosure with a filtered ventilating fan.

Scheduling and recording of experimental sessions and data analysis were accomplished by a system of solid-state digital logic modules and a general-purpose digital computer. Shock was delivered by a constant-peak-current shock generator and scrambled through the cage floor grids, lever, and front and back walls $60 \mathrm{times} / \mathrm{sec}$. Shock intensity was maintained at $5.0 \pm 0.5 \mathrm{~mA}$, and shock duration was $0.5 \mathrm{sec}$.

Pressure sessions and a number of baseline sessions were conducted with the rat cage mounted inside a steel hyperbaric chamber. The chamber was provided with several threaded openings to permit connections to the gas supply, scheduling equipment, and monitoring instruments. The three gases used in the study (nitrogen, helium, and oxygen) were supplied from an externally located gas bank to the chamber through a system of pressure-reducing valves and regulators. A gas recirculator and scrubber unit assured rapid mixing of chamber gases and forced the chamber atmosphere through a carbon dioxide absorbent to control carbon dioxide accumulation. Carbon dioxide level was monitored by an infrared carbon dioxide analyzer which was continuously provided with a $350-\mathrm{cc} / \mathrm{min}$ flow of chamber gas through a flow gauge. Oxygen was monitored by a paramagnetic oxygen analyzer, which was also continuously provided with a $350-\mathrm{cc} / \mathrm{min}$ flow of chamber gas. Before each pressure session, both oxygen and carbon dioxide measuring systems were calibrated with accurately known standard gas mixtures. A system of heating and cooling coils inside the chamber thermostatically maintained the chamber temperature at $25^{\circ} \pm 2^{\circ} \mathrm{C}$. Chamber pressure was measured with a high-pressure gauge connected to the chamber.

\section{Procedure}

Baseline sessions. The subjects were trained to press the response lever to avoid shock presentation according to the free-operant avoidance procedure described by Sidman $(1953,1966)$. The time interval between a response and the next scheduled shock presentation (response-shock interval) was 20 sec. That is, each recorded response postponed the occurrence of the next shock for $20 \mathrm{sec}$, and continuous responding with at least one response within each 20 -sec interval continuously avoided shock. The interval between successive shocks in the absence of responses (shock-shock interval) was $2 \mathrm{sec}$. Each recorded response illuminated the red light above the lever for $0.5 \mathrm{sec}$.

An experimental baseline session lasted for $2 \mathrm{~h}$. Sessions were preceded and followed by a blackout condition of variable length, during which the houselight in the rat cage was off. The subjects performed in the study 5 days per week. Each subject performed on the baseline for a minimum of 50 sessions before exposure to hyperbaric conditions.

Hyperbaric sessions. Each subject was exposed to a series of pressure sessions during which the hyperbaric chamber atmosphere was either a nitrogen-oxygen gas mixture or a helium-oxygen gas mixture. During a single pressure session, the subjects were exposed to five different pressures in ascending pressure. Pressure was measured in terms of pounds per square inch, gauge pressure (psig).

A subject was placed in the rat cage and the hyperbaric chamber was sealed. The subject was allowed to perform for approximately $30 \mathrm{~min}$ on the avoidance schedule to ensure that responding was within baseline ranges. The chamber was then compressed to $89 \mathrm{psi}$ $\left(6.3 \mathrm{~kg} / \mathrm{cm}^{2}\right)$ with the appropriate gas mixture; a subject remained at this pressure for $10 \mathrm{~min}$, during which performance was measured. The pressure in the chamber was next increased to $178 \mathrm{psi}\left(12.5 \mathrm{~kg} / \mathrm{cm}^{2}\right)$ for $10 \mathrm{~min}$, then to $267 \mathrm{psi}\left(18.8 \mathrm{~kg} / \mathrm{cm}^{2}\right.$;, $356 \mathrm{psi}\left(25.0 \mathrm{~kg} / \mathrm{cm}^{2}\right)$, and finally $445 \mathrm{psi}\left(31.3 \mathrm{~kg} / \mathrm{cm}^{2}\right)$, each for $10 \mathrm{~min}$. These five pressures are equal to $7.1,13.1,19.2,25.2$, and 31.3 atmospheres absolute (ATA) and are equivalent to the pressures obtained at depths of $61,122,183,244$, and $305 \mathrm{~m}$ of sea water. Compression rate to each desired pressure was $13.4 \mathrm{psi}$ $\left(0.94 \mathrm{~kg} / \mathrm{cm}^{2}\right)$ per minute. The major proportion of the breathing mixture at all pressures consisted of either nitrogen or helium. The nitrogen-oxygen or helium-oxygen mixtures were obtained by controlling flow rates of each of the pure components while monitoring the exact gas composition with the oxygen analyzer. The oxygen component of the gas mixture was kept constant at $2 \times 10^{-1}$ ATA (normal atmospheric level) at all five pressures. This allowed for the measurement of the effects of increased nitrogen or helium pressures on avoidance performance without concurrent increases in oxygen partial pressure. Levels of carbon dioxide were maintained below $5 \times 10^{-4}$ ATA. Following exposure time to the largest pressure, the houselight was cut off in the rat cage and the pressure session was terminated. Decompression from the $445 \mathrm{psi}$ pressure was then performed according to an appropriate decompression schedule (Thomas, Conda, Armstrong, Wooley, \& Walsh, Note 2). An entire pressure session, including decompression time, lasted approximately $7 \mathrm{~h}$.

Subjects were exposed to several pressure sessions, breathing both the nitrogen-oxygen mixture and the helium-oxygen mixture. The subjects were exposed to each of the gas mixtures for three to six pressure sessions and were exposed to the two gases in different orders and in a semirandom sequence. A minimum of seven baseline sessions occurred between successive pressure sessions.

Data analysis. At each 10 -min pressure exposure during a pressure session, the total number of avoidance responses and shocks, as well as the distribution of responses during the 20 -sec R-S interval in 102 -sec interresponse time bins, were separately recorded. Response rates (responses/sec) and shock frequencies (shocks/sec) were calculated for each $10-$ min pressure exposure for a given pressure session. Each subject's response rates were combined and averaged separately for all three to six exposures for a particular pressure of either nitrogen or helium exposures. This response rate value was used as a measure of performance at each pressure for further data analysis. Shock frequencies and interresponse time distributions were similarly averaged for all exposures at a particular pressure for both gas mixtures. On-line cumulative recordings of avoidance performance were continually obtained.

\section{RESULTS}

Avoidance response rates (responses/sec) increased differentially with elevations in nitrogen and helium pressures. Baseline response rates and rates for each nitrogen and helium pressure are shown in Figure 1. The baseline value represents the mean response rate of all baseline sessions preceding hyperbaric sessions. A significant nitrogen effect was obtained, $F(5,35)=$ 23.09, $p<.001$, consisting of an increase in avoid ance response rates above baseline rate followed by a decline in rates as a function of increasing pressures of nitrogen. Subsequent $t$ tests indicated significant differences between nitrogen pressure means and the baseline mean as shown in Figure 1. A significant helium effect was also obtained, $F(5,35)=32.33$, $\mathrm{p}<.001$. Avoidance response rates did not begin to increase until $267 \mathrm{psi}$, and then increased further with increases in helium pressure. Only at 356 and 445 psi were the helium pressure means significantly different 


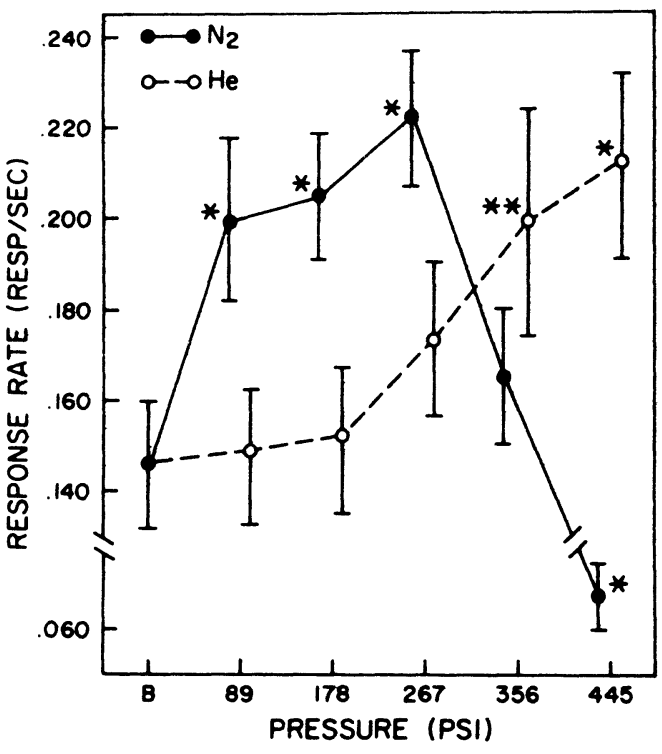

Figure 1. Avoidance response rates (responses/sec) for baseline sessions and five different hyperbaric pressures breathing nitrogen and helium. Each data point is the mean of eight subjects, and brackets indicate standard errors. Asterisks indicate pressure values that differ significantly from baseline: $* *=p<.05, *=$ $\mathbf{p}<.01$.

from the baseline mean as shown in Figure 1. The avoidance rates showed a significant pressure effect, $F(5,35)=7.83, p<.001$, and a significant Gas by Pressure interaction, $F(5,35)=34.78, p<.001$. The data, then, indicate that the pressures differentially affected the avoidance rates, depending on the gas breathed at pressure.

Figure 2 shows the shock frequency (shocks/sec) obtained during baseline sessions and at each nitrogen and helium pressure. Shock frequency changes while breathing increased pressures of nitrogen indicated a significant effect, $F(5,35)=$ $32.33, \mathrm{p}<.001$. Shock frequency declined with increases in nitrogen pressure and then increased at the highest pressures. A comparison of nitrogen pressure means with the baseline mean indicated that only the 445 psi differed significantly, as shown in Figure 2. Shock frequency showed a significant helium effect, $F(5,35)=4.0, p<.01$; however, there were few changes in overall shock frequency when the subjects were exposed to increased helium pressures, except at 445 psi, where shock frequency declined. The shock frequency changes showed an overall significant pressure effect, $F(5,35)=24.36, p<.001$, a significant gas effect, $F(1,7)=18.41, \mathrm{p}<.01$, and a significant $\mathrm{Gas}$ by Pressure interaction, $F(5,35)=$ $34.54, \mathrm{p}<.001$. Thus, the changes in shock frequencies were similar to changes in the avoidance response rates in that the pressures differentially affected the shock occurrences, depending on the gas breathed under pressure.

Representative cumulative response records of a subject at increased pressures of nitrogen and helium are presented in Figure 3. The cumulative records show examples of increases in response rates with increases in nitrogen pressures, with a decline in rate at the highest pressure. The cumulative record from the highest nitrogen pressure (445 psi) also shows the increased shock frequency. The cumulative records show less increases in avoidance response rates with increases in helium pressure until the higher helium pressures.

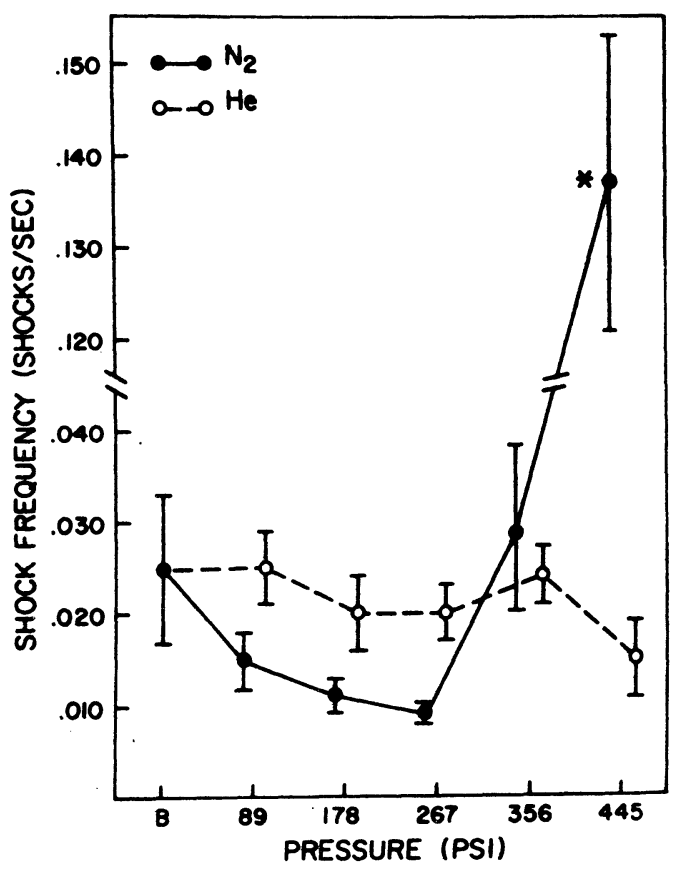

Figure 2. Shock frequencies (shocks/sec) for baseline sessions and five different hyperbaric pressures breathing nitrogen and helium. Each data point is the mean of eight subjects, and brackets indicate standard errors. The asterisk indicates the pressure value that differs significantly $(p<.01)$ from baseline.

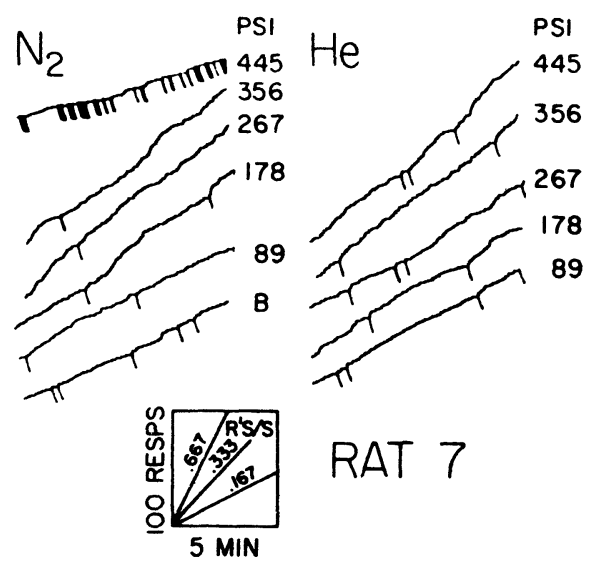

Figure 3. Ten-minute regments of cumulative avoidance response records of Subject 7 from baceline seacion and from raibed presures of nitrogen $\left(\mathbf{N}_{2}\right)$ during a nitrogen presciure seablon and from raised preseures of helium (He) during a hellum presare resaion. Diagonal marks abong the reconds indleate shock occurrences. 
The presence or absence of a temporal discrimination was based upon the amount of time between successive responses recorded in the 10 interresponse time bins. The conditional probability of the frequency of interresponse times in a bin divided by the number of opportunities that a subject had to respond in that interresponse time bin was used as a measure of interresponse time probabilities and temporal discrimination (Anger. 1963: Sidman. 1966). When interresponse times per opportunity are plotted as a function of interresponse times, temporal discrimination is indicated by an increasing function as interresponse times approach shock occurrence time. Interresponse time plots are shown in Figure 4 for baseline and all pressures of both nitrogen and helium. The plots indicate rather well-developed temporal discrimination on baseline sessions. The temporal discrimination remained fairly intact at 89 and $1^{-8} 8 \mathrm{psi}$ for both nitrogen and helium. From $26^{-}$psi through the two higher pressures, the temporal discrimination declined under nitrogen. with only minimal evidence of a discrimination at the highest nitrogen pressure (445 psi). The temporal discrimination remained fairly well developed for all pressures of helium. including the highest helium pressure.

\section{DISCUSSION}

Aroidance response rates generated by the tree-operant avoidance schedule increased under raised pressures of nitrogen up to 19 times that of normal atmospheric pressure (267 psi). Further increases in nitrogen pressures produced decreases in aroidance rates with associated increases in shock frequency. The observed changes in response rates and shock frequencies appeared to be directly related to increases in the nitrogen partial pressure, as both oxygen and carbon dioxide partial pressures were maintained at normobaric levels. Changes in avoidance rates were not related to increases in total absolute pressure per se. as similar changes did not occur at identical elevated pressures with helium as the breathing medium. Although avoidance response rates declined from 356 to $445 \mathrm{psi}$. it is of significance that some responding was maintained under such nitrogen pressures. This is the first clear behavioral demonstration that organisms are capable of operant performance while breathing nitrogen at such high pressures. which are equal to those occurring at depths of $30 \Sigma \mathrm{m}(1.000 \mathrm{ft})$ of sea water.

The avoidance behavior was affected differently by raised helium pressures than by raised nitrogen pressures. Rates of responding remained near baseline rates under helium up to pressures of $26^{-}$psi. The effects of elevated partial pressures of helium at 356 to 445 psi on avoidance rates were much like those of nitrogen pressures at 89 to 178 psi.

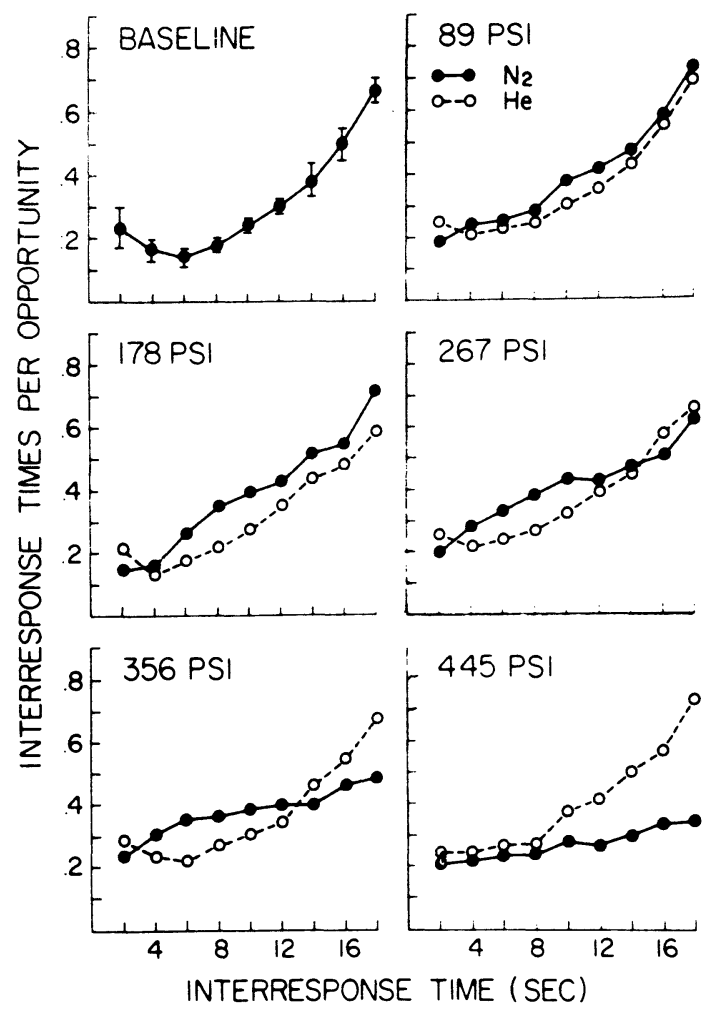

Figure 4. Interresponse times per opportunity for each interresponse time bin obtained for baseline seasions and breathing either nitrogen $\left(\mathrm{N}_{2}\right)$ or helium $(\mathrm{He})$ at five elevated pressures. Each interresponse time bin is 2 sec in length. Each data point is the mean of eight subjects, and brackets for baseline sessions indicate standard errors.

This is in accord with the notion that nitrogen is about four times as potent as helium in terms of narcotic potency (Bennett. 1966. 1969).

There is no clear statement that can be made at present to account for increased avoidance responding under hyperbaric conditions. The increase in aroidance rates under increased nitrogen pressures up to 267 psi was not associated with any clear disruption in the temporal discrimination on the avoidance schedule. as indicated by the conditional probabilities of the interresponse time distributions. As demonstrated previously (Thomas \& Burch, 1975). increases in avoidance response rates by moderately elevated pressures of nitrogen do not appear to be related to loss of or changes in the temporal discrimination. This also appears to hold for helium at the higher pressures. where aroidance rates increased but temporal discrimination remained intact. The increases in avoidance rates under raised nitrogen pressures were probably not related to any pressure-enhancement in the aversiveness of the shock. The threshold response in rats to minimal electric shock and the pain threshold to electrical stimulation are increased under increased pressures of nitrogen (Bennett. 1963: Lazarer. Lyublina, \& 
Madorskaya, 1948), which suggests that the aversive aspects of shock become lessened rather than enhanced under raised nitrogen pressures. Results of previous studies have suggested that increased avoidance rates as well as increased response rates on other operant schedules may be due to a direct effect of increased pressures of nitrogen (Thomas \& Burch, 1975; Walsh, 1974). That is, nitrogen may have direct stimulatory or excitatory effects on behavior, rather than the commonly attributed depressant effect. Another consideration is that increased response output under elevated pressure is dependent upon control baseline values, as has been found for many chemical and pharmacological effects on response output (Kelleher \& Morse, 1968). Studies have shown that low rates of responding generated by schedules of reinforcement (such as DRL schedules) increase under pressure (Jennings, 1973; Thomas, 1973a, 1974; Walsh \& Bachrach, 1974; Thomas, Walsh, \& Bachrach, Note 1). Other studies show that high rates of responding generated by schedules such as fixed-ratio schedules decline under pressure (Jennings, 1973; Thomas, 1973b; Thomas, Walsh, \& Bachrach, Note 3). The increases in avoidance response rates under increased pressures in the present and previous avoidance study may thus depend upon the level of the baseline response rate generated by the avoidance schedule.

Generally, increases in nitrogen partial pressure produced an increase in avoidance response rates up to a maximum pressure beyond which further pressure increments produced a decline in response rates. Temporal discrimination on the avoidance schedule remained well developed up to the nitrogen pressure maximum and was almost completely absent at higher nitrogen pressures. Although mention of a descriptive pressure-response curve is most parsimonious, it seems that the decline in avoidance response rates at higher nitrogen pressures is qualitatively different enough to suggest that the decline is related to other mechanisms than those producing rate increases. The response-rate changes change direction at the higher nitrogen pressures, shock frequency increases, and the temporal discrimination becomes disrupted. The decline in response rates with associated increases in shock frequency may be due to the direct effect of increased nitrogen pressures in disrupting the temporal discrimination. The disruption of response rates at the high nitrogen pressures also could be due to the narcotic or anesthetic effects of nitrogen at these pressures (Brauer \& Way, 1970; Lazarev et al., 1948; Marshall, 1951), which may physically prevent responding. Another account for lowering of response output is the analgesia (Carpenter, 1953; Lazarev et al., 1948) produced by an increase of 30 times the normal atmospheric pressure of nitrogen, which could reduce the effectiveness of the electric shock as a negative reinforcer and thus allow for breakdown in the maintenance of avoidance behavior.

\section{REFERENCE NOTES}

1. Thomas, J. R., Walsh, J. M. Bachrach, A. J., \& Thorne, D. R. Differential behavioral effects of nitrogen, helium, and neon at increased pressures. Paper presented at the Fifth Symposium on Underwater Physiology, Freeport, Grand Bahama Islands, August 1972.

2. Thomas, J. R., Conda, K. J., Armstrong, F. W., Woolley, J. M., \& Walsh, J. M. Decompression schedules for use in behavional studies with laboratory rats. Naval Medical Research Institute Report No. 3, Project No. MF12.524.004.7007D, Bethesda, Maryland, October 1973.

3. Thomas, J. R., Walsh, J. M., \& Bachrach, A. J. Effects of breathing air and helium-oxygen at several depths on response rates in multiple schedules. Naval Medical Research Institute Report No. 1, Project No. MF12.524.004.7007D, Bethesda, Maryland, December 1971.

\section{REFERENCES}

ANGER, D. The role of temporal discrimination in the reinforcement of Sidman avoidance behavior. Journal of the Experimental Analysis of Behavior, 1963, 6, 477-506.

Behnke, A. R., Thompson, R. M., \& Motrey, E. P. Psychologic effects from breathing air at four atmospheres pressure. American Journal of Physiology, 1935, 112, 554-558.

BehNKe, A. R., \& YARbrough, O. D. Respiratory resistance, oilwater solubility and mental effects of argon compared with helium and nitrogen. American Journal of Physiology, 1939, 126, 409-415.

BENNETT, P. B. Prevention in rats of the narcosis produced by inert gases at high pressures. American Journal of Physiology, 1963, 205, 1013-1018.

Bennet, P. B. The narcotic action of inert gases. In O. G. Edholm \& A. L. Bacharach (Eds.), The physiology of human survival. London and New York: Academic Press, 1965. Pp. 164-182.

BENNETT, P. B. The aetiology of compressed air intoxication and inert gas narcosis. London: Pergamon Press, 1966.

BennetT, P. B. Inert gas narcosis. In P. B. Bennett \& D. H. Elliott (Eds.), The physiology and medicine of diving and compressed air work. Baltimore: Williams \& Wilkins, 1969. Pp. 155-182.

BRAUER, R. W., \& WAY, R. O. Relative narcotic potencies of hydrogen, helium, nitrogen, and their mixtures. Journal of Applied Physiology, 1970, 29, 23-31.

CARPENTER, F. G. Depressant action of inert gases in CNS in mice. American Journal of Physiology, 1953, 172, 471-474.

Frankenhaeuser, M., Graff-Lonnevig, V., \& Hesser, C. M. Psychomotor performance in man as affected by high oxygen pressure (3 atmospheres). Acta Physiologia Scandinavica, $1960,50,1.7$.

Frankenhaeuser, M., Graff-Lonnevig, V., \& Hesser, C. M. Effects on psychomotor functions of different nitrogen-oxygen gas mixtures at increased ambient pressure. Acta Physiologia Scandinavica, 1963, 59, 400-409.

Jennings, R. D. Nitrogen narcosis and rat behavior on fixed-ratio and differential-reinforcement-of-low-rate schedules. Journal of Comparative and Physiological Psychology, 1973, 83, 515-522.

Kelleher, R. T., \& MoRse, W. H. Determinants of the specificity of behavioral effects of drugs. Ergebnisse der Physiologie, Biologischen Chemie und Experimentellen Pharmakologie, 1968, 60, 1-56.

Lazarev, N. V., Lyublina, E. I., \& Madorskaya, R. Y. Biological actions of gases under pressure. Fiziologicheskii Zhurnal S.S.S.R., 1948, 34, 130.

Marsilall, J. M. Nitrogen narcosis in frogs and mice. American Journal of Physiology, 1951, 166, 699-711.

Miles, S. Underwater medicine. Philadelphia: Lippincott, 196. Pp. 110-127.

Sidman, M. Two temporal parameters of the maintenance of avoidance behavior by the white rat. Journal of Comparative and Physiological Psychology, 1953, 46, 253-261. 
Sidman, M. Avoidance behavior. In W. K. Honig (Ed.), Operant behavior: Areas of research and application. New York: Appleton-Century-Crofts, 1966. Pp. 448-498.

Tномаs, J. R. Nitrogen, helium, and neon effects on timing behavior at increased pressures. Aerospace Medicine, 1973, 44. 45-48. (a)

Thомаs, J. R. Amphetamine and chlordiazepoxide effects on behavior under increased pressures of nitrogen. Pharmacology, Biochemistry, and Behavior, 1973, 1, 421-426. (b)

Tномаs, J. R. Combined effects of elevated pressures of nitrogen and oxygen on operant performance. Undersea Biomedical Research, 1974, 1, 363-370.

Thomas, J. R., \& BuRch, L. S. Free-operant avoidance in rats under increased nitrogen pressures. Journal of Comparative and Physiological Psychology, 1975, 88, 862-867.

W ALSH, J. M. Amphetamine effects on timing behavior in rats under hyperbaric conditions. Aerospace Medicine, 1974, 45, 721-726.
Walsh, J. M., \& Bachrach, A. J. Adaptation to nitrogen narcosis manifested by timing behavior in the rat. Journal of Comparative and Physiological Psychology, 1974, 86, 883-889.

\section{NOTE}

1. The animals used in this study were handled in accordance with the provisions of Public Law 89-44 as amended by Public Law $91-579$, the "Animal Welfare Act of 1970," and the principles outlined in the "Guide for the Care and Use of Laboratory Animals," U.S. Department of Health, Education and Welfare Publication No. (NIH) 73-23.

(Received for publication February 12, 1975; revision accepted July 1, 1975.) 